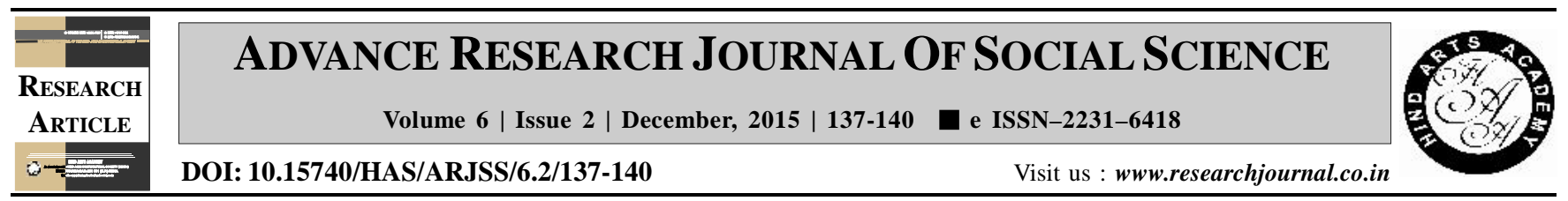

\title{
Paternal involvement in child rearing activities of pre-school children
}

S. Kartik* and S. Gir

Department of Human Development and Family Studies, College of Home Science, Maharana Pratap University of Agriculture and Technology, UDAIPUR (RAJASTHAN) INDIA

(Email : sksonali777@gmail.com)

\section{ARTiCLE INFO :}

$\begin{array}{lll}\text { Received } & : & 05.06 .2015 \\ \text { Revised } & : & 11.10 .2015 \\ \text { Accepted } & : & 24.10 .2015\end{array}$

KEY WORDS :

Father's involvement, Child rearing activities, Male and female pre-school children

HOW TO CITE THIS ARTICLE : Kartik, S. and Gir, S. (2015). Paternal involvement in child rearing activities of pre-school children. Adv. Res. J. Soc. Sci., 6 (2) : 137-140.

*Author for correspondence

\begin{abstract}
In the past few decades, enormous changes have occurred in gendered divisions of household activities and child care across many countries with a growing consensus that there is a slow but steady pace of change in gendered division of time and tasks but one that is combined with a puzzling persistence of gender differences in parental caregiving responsibilities. The present study was an attempt to assess the level of father's involvement in selected child rearing activities of their male and female preschool children under 2-6 years of age as their eldest offspring. The total sample consisted of 120 fathers, out of which 60 fathers were having boys as their index child and 60 fathers were having girls as their eldest child. Paternal involvement inventory was used by the investigator to assess the level of fathers' involvement in child rearing tasks of their pre-school children. Z- Test for difference between two means was administered and no significant difference was found in the level of father's involvement in child rearing of male and female pre-school children.
\end{abstract}

